\title{
CHARACTERISTICS OF NANO ROSETTE TiO2 HYDROTHERMALLY GROWN ON A GLASS SUBSTRATE AT DIFFERENT REACTION TIMES AND ACID CONCENTRATIONS
}

\author{
Nofrijon Sofyan $^{1 *}$, Aga Ridhova ${ }^{1}$, Akhmad Herman Yuwono $^{1}$, Joseph $\mathrm{Wu}^{2}$ \\ ${ }^{1}$ Department of Metallurgical and Materials Engineering, Faculty of Engineering, Universitas \\ Indonesia, Kampus UI Depok, Depok 16424, Indonesia \\ ${ }^{2}$ College of Engineering, Mathematics and Science, University of Wisconsin-Platteville, Wisconsin \\ 53818, USA
}

(Received: July 2018 / Revised: August 2018 / Accepted: September 2018)

\begin{abstract}
The characteristics of nano rosette $\mathrm{TiO}_{2}$ hydrothermally grown on a glass substrate at different reaction times and acid concentrations has been examined. The hydrothermal reaction was performed at $170^{\circ} \mathrm{C}$ for $3,4,5$, and 6 hours whereas the crystallization was achieved through calcination at $450^{\circ} \mathrm{C}$ for 90 minutes. The growth mechanism was observed by employing the hydrothermal reaction under different acid concentrations: $0 \%, 12.5 \%, 25 \%$, and $50 \% \mathrm{v} / \mathrm{v} \mathrm{HCl}$. The morphology, formation, crystallization, and growth mechanism of the nano rosette $\mathrm{TiO}_{2}$ were characterized using a field emission scanning electron microscope (FE-SEM) and X-ray diffraction (XRD). The electron images showed that after 3 hours of hydrothermal reaction time, the nucleation process has just taken place; the formation of the nano rosette was completed after 6 hours. The results also showed that the acid environment plays a dominant role in determining the three-dimensional (3D) architecture of the nano rosette $\mathrm{TiO}_{2}$. Structural studies from XRD showed that different acid concentrations resulted in different crystalline formations. The nano rosette rutile $\mathrm{TiO}_{2}$ crystal structure was formed after 6 hours of hydrothermal reaction under $1: 1$ distilled water and $\mathrm{HCl}$ with a structure indexed to rutile $\mathrm{P} 42 / \mathrm{mnm}$ with lattice parameters of $a=4.557(6) \AA$ and $c=2.940(5) \AA$.
\end{abstract}

Keywords: Growth mechanism; Hydrothermal; Nano rosette; Rutile; Titania

\section{INTRODUCTION}

In the last several years, the self-assembly architecture of nanoscale building blocks has attracted the attention of many researchers for use in many nanostructured multifunctional materials. The nanoscale building blocks are usually in the forms of one-dimensional (1D), 2D, or 3D architectures of hierarchical nanostructures. The 3D architectures, especially 3D nanostructures assembled from 1D and 2D nanoscales to form building blocks, have become a hotspot and received special attention due to their unique properties and promising applications (Jia et al., 2017). These 3D nanostructures include nanowires (Zhu et al., 2018), nanorods (Govindaraj et al., 2017), nanosheets (Zhong et al., 2015), and nanoflowers (Ma et al., 2017).

One of the compounds that has attracted the attention of many researchers interested in nanostructured multifunctional application is titanium dioxide $\left(\mathrm{TiO}_{2}\right)$. Titanium dioxide is a polymorph compound that has several crystal structures with unique properties. Depending on

\footnotetext{
*Corresponding author's email: nofrijon@metal.ui.ac.id, Tel. +62-21-7863510, Fax. +62-21-7872350 Permalink/DOI: https://doi.org/10.14716/ijtech.v9i6.2345
} 
how it is formed, $\mathrm{TiO}_{2}$ may have brookite, anatase, and or rutile crystal structures (Banfield \& Veblen, 1992). Due to these unique properties, many researchers have had numerous breakthroughs in the wide range of applications for $\mathrm{TiO}_{2}$. For example, $\mathrm{TiO}_{2}$ has been applied in the fields of sensors (Bai \& Zhou, 2014), photocatalysts (Nakata \& Fujishima, 2012), environmental remediation (Ochiai \& Fujishima, 2012), photovoltaic cells (Hagfeldt \& Grätzel, 1995), batteries (Longoni et al., 2017), and some other electrochemical devices (Yasin et al., 2016).

Among the several structures of $\mathrm{TiO}_{2}$, rutile is more thermodynamically stable than the other two forms of anatase and brookite. This is especially true because the two other crystal structures will transform to rutile when heated at $600-700^{\circ} \mathrm{C}$ (Hanaor \& Sorrel, 2011). Nevertheless, each of these structures has its own application. For example, anatase is usually considered to be the most photoactive of the three polymorphs and thus it is used for the degradation of organic pollutants (Wang et al., 2015; Fisli et al., 2017) and dye-sensitized solar cells (Hagfeldt \& Grätzel, 1995; Sofyan et al., 2017); brookite also has an application in the field of photocatalysis (Xie et al., 2009), whereas rutile is usually used the most in perovskite solar cells (Saif et al., 2012).

Recently, the use of the 3D nanostructures of $\mathrm{TiO}_{2}$, specifically the hierarchical flower-like $\mathrm{TiO}_{2}$ nanostructures, has increased due to their unique and excellent optical, electrical, and electronic properties ( $\mathrm{Bu}$ et al., 2015). Many investigators have tried to find a facile way to synthesize the 3D flower-like nanostructures of $\mathrm{TiO}_{2}$ that are useful in many applications. For example, the 3D nano-flower hierarchical structures of $\mathrm{TiO}_{2}$ have been proven to enhance its photocatalytic properties (Zhou et al., 2013). Xiao et al. (2017) and Govindasamy et al. (2016) have reported that the use of a combination of compact $\mathrm{TiO}_{2}$ layers with the growth of $\mathrm{TiO}_{2}$ nanorods as an electron transporting layer has improved the performance of perovskite solar cells.

Most of the problems being faced by the investigators in synthesizing the $3 \mathrm{D}$ hierarchical flower-like structures of $\mathrm{TiO}_{2}$ concern the homogeneity and the coverage area for the case of deposition process. Many papers discuss the transformation of anatase to the rutile form or vice versa, but very few references discuss the direct synthesis of rutile with high homogeneity, especially in the form of rutile nano rosette $\mathrm{TiO}_{2}$. In this work, we have grown 3D hierarchical nano rosette $\mathrm{TiO}_{2}$ through a hydrothermal process on a glass substrate with enhanced homogeneity and coverage area that has promising applications in photocatalysis or in an electron transporting layer in perovskite solar cells. This paper presents and discusses the characteristics of nano rosette $\mathrm{TiO}_{2}$ made from different hydrothermal reaction times, the degree of crystallization from different calcination times, and the effect of the environmental condition during the hydrothermal process on the growth of nano rosette $\mathrm{TiO}_{2}$ as controllable variables during the synthesis.

\section{METHODS}

Nano rosette $\mathrm{TiO}_{2}$ was synthesized through deposition on top of a fluorine-doped tin oxide (FTO, $30 \Omega / \mathrm{cm}^{2}$ ) glass substrate via a hydrothermal method similar to the previously reported procedure used by Govindasamy et al. (2016) with a slight modification. In a typical synthesis, distilled water was mixed with hydrochloric acid at a fixed volume ratio of 1:1 to reach a total volume of $40 \mathrm{~mL}$ in a beaker glass. The mixture was then treated ultrasonically (Digital Ultrasonic Cleaner, Krisbow) under ambient condition for 5 minutes. A volume of $450 \mu \mathrm{L}$ of titanium (IV) isopropoxide (TTIP) was added to the previous mixture, followed by another ultrasonic mix for 5 minutes to get a clear solution. The glass substrate was ultrasonically treated for 10 minutes in a mixed solution of distilled water, acetone, and ethanol with volume 
ratios of 1:1:1. The glass substrate was then placed horizontally on the bottom of a Teflon-lined stainless-steel autoclave $(100 \mathrm{~mL})$ and the mixture of TTIP solution was poured over it. The hydrothermal synthesis was conducted at $170^{\circ} \mathrm{C}$ for $3,4,5$, and 6 hours in a vacuum oven (DZF-6050, Berkeley Scientific). After the synthesis, the autoclave was cooled to room temperature under flowing water for approximately 5 minutes. The glass substrate was taken out and rinsed with distilled water and allowed to air dry for 15 minutes before being calcined using a hot-plate (Cimarec SP 131320-33, Thermo Scientific) at $450^{\circ} \mathrm{C}$ for 90 minutes, when it was ready for characterization.

The hydrothermal reaction with different acid concentrations was employed to observe the growth mechanism of nano rosette $\mathrm{TiO}_{2}$. The synthesis method used the same hydrothermal reaction time, but different solvents. For the solvents, distilled water was mixed with a certain volume of hydrochloric acid, i.e. $0,5,10$, and $20 \mathrm{~mL}$ to reach a total volume of $40 \mathrm{~mL}$ in a beaker glass. These solvent mixtures were then marked as $0 \%, 12.5 \%, 25 \%$, and $50 \% \mathrm{v} / \mathrm{v} \mathrm{HCl}$, respectively. The subsequent process to grow $\mathrm{TiO}_{2}$ followed the process described above for the hydrothermal reaction.

The characteristics of the sample were examined using a field emission scanning electron microscope (FE-SEM, FEI Inspect F50) and X-ray diffraction (XRD, PANalytical X'Pert PRO) operating at $40 \mathrm{kV} 30 \mathrm{~mA}$ with $\mathrm{Cu} \mathrm{K} \alpha$ radiation $(\lambda=1.5406 \AA)$.

\section{RESULTS AND DISCUSSION}

The morphology of hydrothermally synthesized $\mathrm{TiO}_{2}$ made with different reaction times was studied through secondary electron images taken using a FE-SEM and the results are shown in Figure 1. To measure the rosette petal size, high resolution secondary electron images were also taken and are displayed in the inset. As can be seen in Figure 1a for the hydrothermal reaction of 3 hours, the nucleation has just started and the coverage area is very small. Some of the clusters have started orientating themselves to form irregular nano rosettes with an average petal diameter of $60 \mathrm{~nm}$. More coverage area is found in the 4-hour hydrothermal reaction (Figure 1b). At this 4-hour reaction time, the crystals have oriented and assembled themselves to form a more regular nano rosette crystal structure with an average petal diameter of $80 \mathrm{~nm}$. In 5 hours of hydrothermal reaction time (Figure 1c), the full substrate coverage can be seen; however, the formation of the nano rosette crystal structure has not been entirely completed. Some of the crystals are at their early rosette formation and lie on the substrate base. The complete rosette formation at this 5-hour hydrothermal reaction time has an average petal size of $110 \mathrm{~nm}$. Complete nano rosette crystal formation with full substrate coverage is found in the hydrothermal reaction time of 6 hours (Figure 1d). At this stage, the petal of the rosette has reached an average size of about $300 \mathrm{~nm}$. It is obvious from this morphology study that the longer the reaction time, the larger the crystal size.

Figure 2 shows the secondary electron images of $\mathrm{TiO}_{2}$ grown hydrothermally at $170^{\circ} \mathrm{C}$ for 6 hours under different acid concentrations, i.e. $0 \%, 12.5 \%, 25 \%$, and $50 \% \mathrm{v} / \mathrm{v} \mathrm{HCl}$. High resolution images were taken to measure the petal size, shown in the inset. Using pure distilled water and no acid, the covered area has a layer with just nanoparticles and no trend to form a larger 3D shape (Figure 2a). The average particle size is about $20 \mathrm{~nm}$. Some these particles clump together, forming rod-like shapes. The tendency to form a 3D hierarchical structure starts with the addition of an acid concentration of $12.5 \% \mathrm{v} / \mathrm{v} \mathrm{HCl}$, as can be seen in Figure $2 \mathrm{~b}$. The initial shape of this 3D structure has begun to form a flower from the clump of nanoparticles, which has an average size of $80 \mathrm{~nm}$. The formation of the 3D architecture with several layers of lotus petal-shaped rosettes is more apparent when $25 \% \mathrm{v} / \mathrm{v} \mathrm{HCl}$ was used, as can be seen in Figure 2c. 

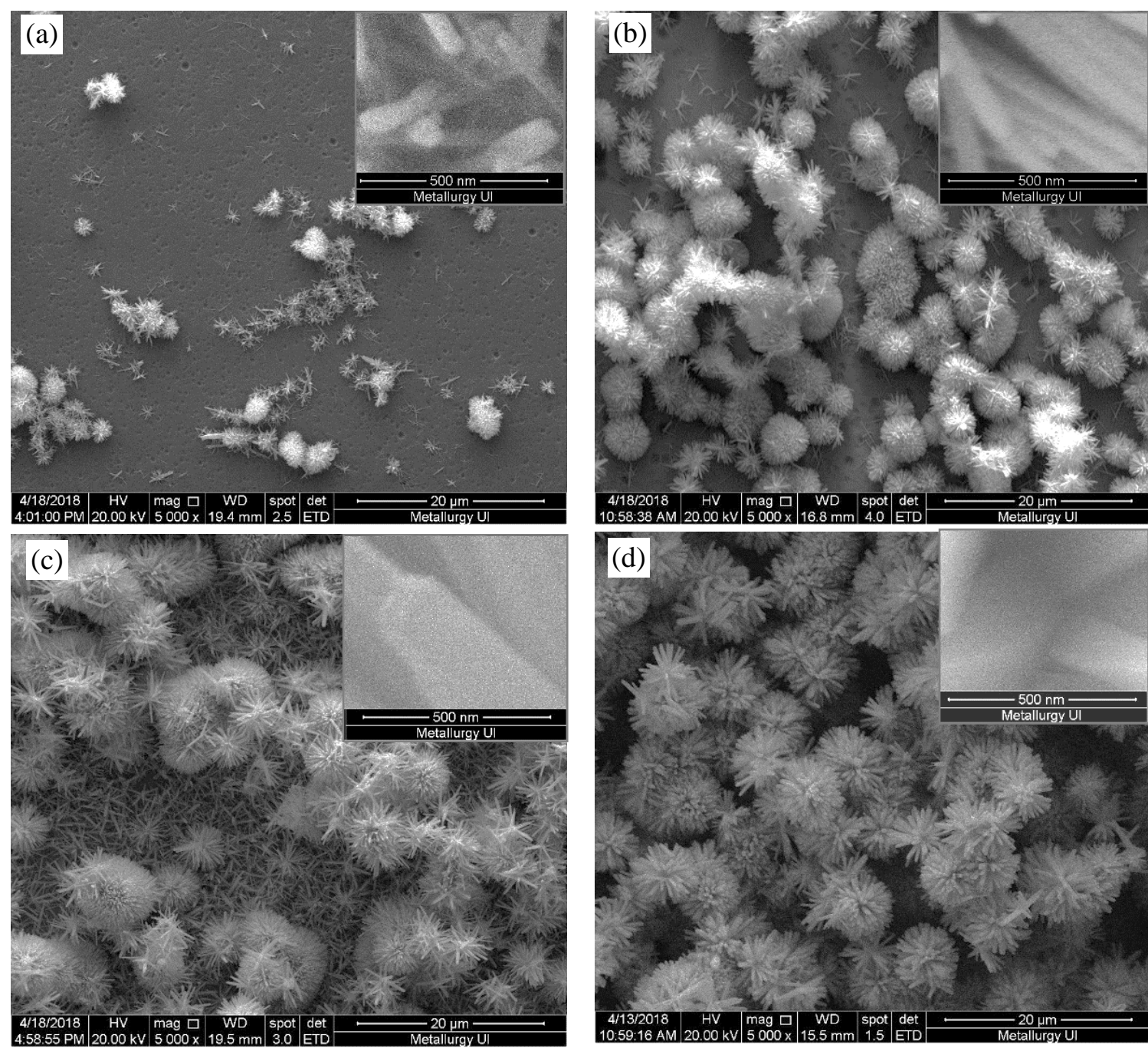

Figure $1 \mathrm{Secondary}$ electron images of nano rosette rutile $\mathrm{TiO}_{2}$ grown hydrothermally at $170^{\circ} \mathrm{C}$ for: (a) 3; (b) 4; (c) 5; and (d) 6 hours. The bar scale is $20 \mu \mathrm{m}$. The differences in the coverage area are apparent: the longer the reaction time, the more the coverage area. The insets are the pictures in high resolution (bar scale $500 \mathrm{~nm}$ )

The average width of the rosette petal is about $150 \mathrm{~nm}$. At a high acid concentration of $50 \% \mathrm{v} / \mathrm{v}$ $\mathrm{HCl}$, the formation of the 3D architecture with Mimosa pudica petal-shaped rosettes is apparent (Figure 2d). As has been mentioned previously, the average width of the rosette petals is about $300 \mathrm{~nm}$. From this morphology study, it is obvious that the acid concentration is a dominant factor in determining the $3 \mathrm{D}$ architecture of the nano rosette $\mathrm{TiO}_{2}$.

The crystal structure and the phase formed during the hydrothermal reaction using different acid concentrations were characterized using the XRD technique after calcination for 90 minutes. Figure 3 shows X-ray diffractograms of $\mathrm{TiO}_{2}$ grown hydrothermally at $170^{\circ} \mathrm{C}$ for 6 hours with the different acid concentrations of $0 \%, 12.5 \%, 25 \%$, and $50 \% \mathrm{v} / \mathrm{v} \mathrm{HCl}$.

The first diffractogram is rutile $\mathrm{TiO}_{2}$ reference (JPDS 01-082-0154) indexed to the $\mathrm{P} 4_{2} / \mathrm{mnm}$ tetragonal crystal structure (Figure 3a). In the second diffractogram (Figure $3 \mathrm{~b}$ ), $\mathrm{TiO}_{2}$ was grown hydrothermally in pure distilled water with no acid; it shows the formation of anatase $\mathrm{TiO}_{2}$, marked by the arrow. The complete diffractogram of this anatase crystal structure is provided in the inset. In the third diffractogram (Figure 3c), $\mathrm{TiO}_{2}$ was grown hydrothermally in a low acid concentration of $12.5 \% \mathrm{v} / \mathrm{v} \mathrm{HCl}$, and it shows the mixed formation of both anatase (arrow) and rutile phases. The fourth and fifth diffractograms, with acid concentrations of $25 \%$ 
(Figure 3d) and 50\% v/v HCl (Figure 3e) respectively, show peaks of a pure rutile phase, but with peak shifting. There were no other characteristics from other phases and or impurities detected. For the peak shifting, the refinement of the crystal structure has been carried out and has resulted in lattice parameters shifting from $a=4.508 \AA$ and $c=3.027 \AA$ to $a=4.557(6) \AA$ and $c=2.940(5) \AA$. This refinement result for the rutile crystal structure agrees with the results found by others (Cargnello et al., 2014).
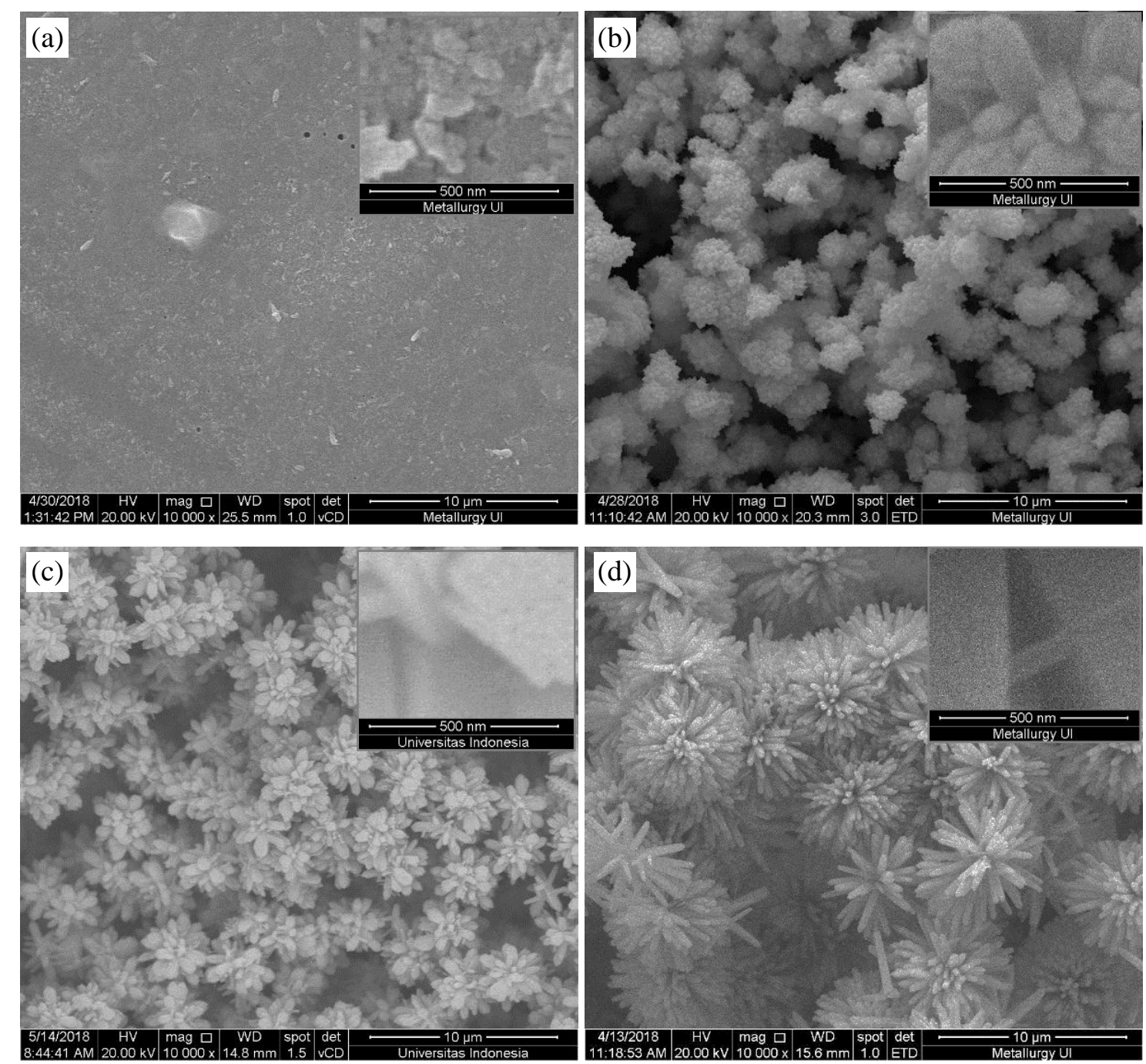

Figure 2 Secondary electron images of $\mathrm{TiO}_{2}$ grown hydrothermally at $170^{\circ} \mathrm{C}$ for 6 hours using different acid concentrations of: (a) $0 \%$; (b) $12.5 \%$; (c) $25 \%$; and (d) $50 \% \mathrm{v} / \mathrm{v} \mathrm{HCl}$. The bar scale is $10 \mu \mathrm{m}$. The insets are the pictures in high resolution (bar scale $500 \mathrm{~nm}$ )

From this structural study, it is also clear that the acid concentration is a dominant factor in determining the crystal structure formation of the nano rosette rutile $\mathrm{TiO}_{2}$, as the morphology study explained previously.

In the absence of an acid environment, there is no driving force for the formation of the 3D hierarchical structure. This is proven by the fact that after the nucleation process and the deposition take place during the hydrothermal reaction, the nuclei tend to adhere to their original shape and stay in the form of nanoparticles. In this instance, a 6-hour hydrothermal reaction only results in the formation of nanoparticle anatase $\mathrm{TiO}_{2}$. This result agrees with the findings of others (Yin et al., 2004). In the presence of an acid environment, however, after the 
nucleation process and the deposition take place, the nuclei still have the energy to grow larger and form 3D hierarchical structures during the hydrothermal reaction. Depending on the acid concentration acting as the driving force for the 3D structure formation, the hydrothermal reaction product could take the form of the flower-like nano rosette rutile $\mathrm{TiO}_{2}$. This result agrees with the result found by others (Yanqing et al., 2001)

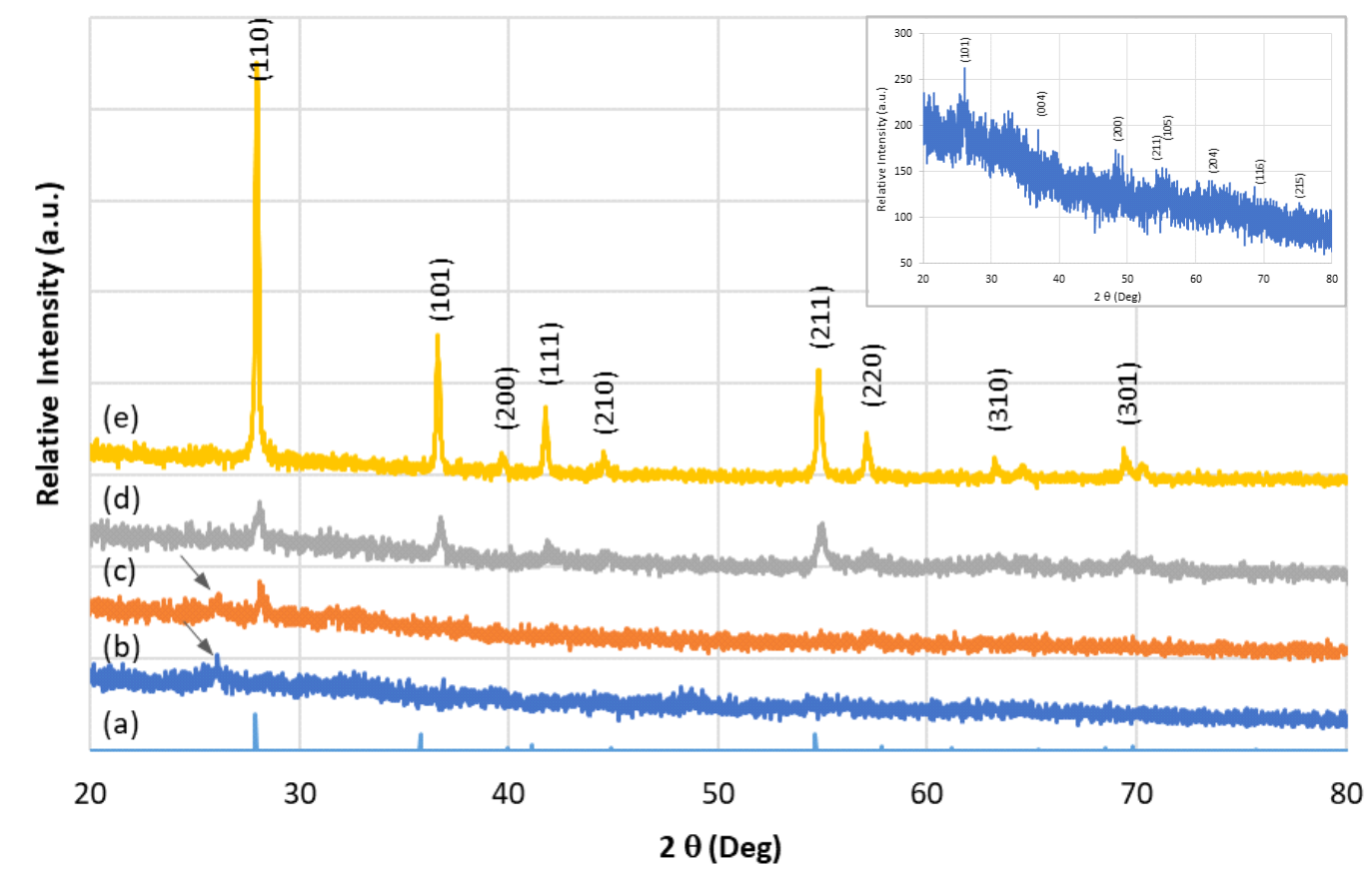

Figure $3 \mathrm{X}$-ray diffractograms of $\mathrm{TiO}_{2}$ grown hydrothermally at various acid concentrations. The first diffractogram at the bottom line (a) is rutile $\mathrm{TiO}_{2}$ reference (JPDS 01-082-0154). In (b) $\mathrm{TiO}_{2}$ was grown hydrothermally in pure distilled water with no acid; the diffractogram shows a tendency of anatase $\mathrm{TiO}_{2}$ (arrow) with the detail given in the inset. In (c), $\mathrm{TiO}_{2}$ was grown hydrothermally in a low acid concentration $(12.5 \% \mathrm{v} / \mathrm{v} \mathrm{HCl})$; the diffractogram shows a mixture of anatase and rutile. In (d) and (e) with acid concentrations of $25 \%$ and $50 \% \mathrm{v} / \mathrm{v} \mathrm{HCl}$ respectively, the diffractograms show a pure rutile formation

In order to understand the growth mechanism during the hydrothermal reaction using different acid concentrations, a formation mechanism is proposed, as schematically illustrated in Figure 4. The scheme illustrates the reaction pathway of the formation of $\mathrm{TiO}_{2}$ (Yanqing et al., 2001). During the hydrothermal reaction, the hydrolysis reaction takes place to form the amorphous phase of $\mathrm{Ti}(\mathrm{OH})_{4}$. Titanium exists as a six-fold coordinated $\left[\mathrm{Ti}\left(\mathrm{H}_{2} \mathrm{O}\right)_{6}\right]^{4+}$ complex. Because both anatase and rutile $\mathrm{TiO}_{2}$ can grow from $\mathrm{TiO}_{6}$ octahedra, the phase formation proceeds through the rearrangement of the octahedra. During the hydrothermal reaction, the $\left[\mathrm{Ti}\left(\mathrm{H}_{2} \mathrm{O}\right)_{6}\right]^{4+}$ hydrated ions are dehydrated and polymerized to form $\left[\left(\mathrm{H}_{2} \mathrm{O}\right)_{5} \mathrm{Ti}-(\mathrm{OH})\right] \mathrm{n}^{3+}$ or $\left[\left(\mathrm{H}_{2} \mathrm{O}\right)_{4} \mathrm{Ti}-\right.$ $\left.(\mathrm{OH})_{2}\right] \mathrm{n}^{2+}$. When TTIP is dissolved in distilled water only, more $\mathrm{OH}-$ are available and thus the rearrangement of the TiO6 octahedra occurs with an edge-sharing mechanism to form an anatase crystal structure. However, when TTIP is dissolved in water in an acid environment, there would be a smaller amount of $\mathrm{OH}-$ and thus the $\mathrm{TiO}_{6}$ octahedra rearrange themselves with a corner-sharing mechanism to form a rutile crystal structure (Yanqing et al., 2001).

Based upon the above reaction pathway during the hydrothermal reaction, a growth mechanism for the $3 \mathrm{D}$ architecture of the nano rosette rutile $\mathrm{TiO}_{2}$ is proposed, as illustrated in Figure 5. 


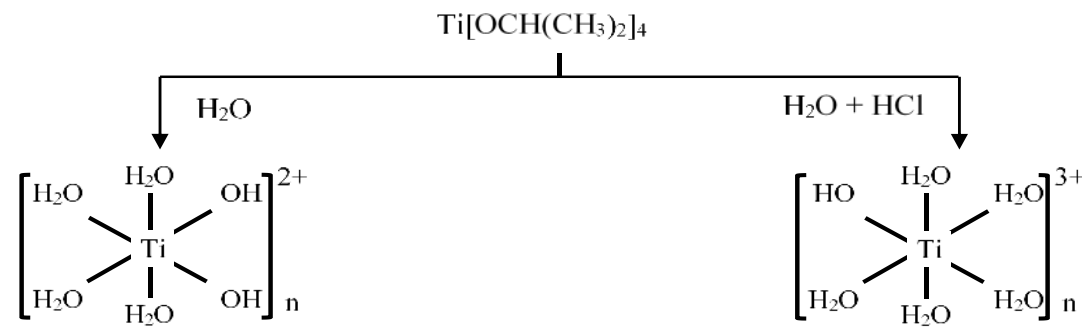

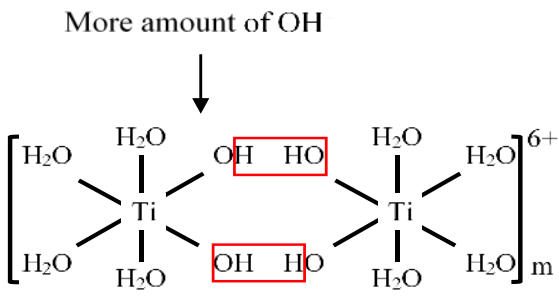

Edge sharing structure

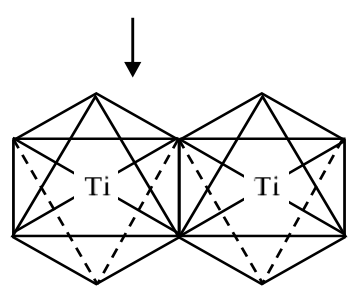

Anatase

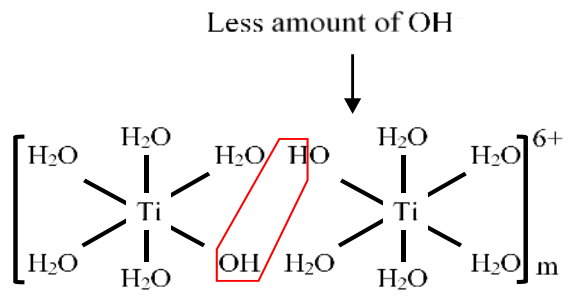

Corner sharing structure

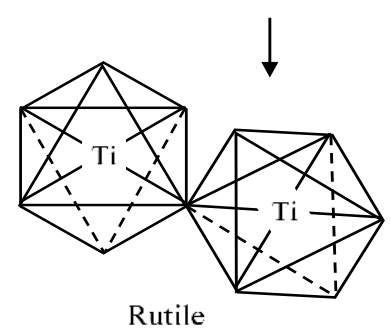

Figure 4 Illustration of the reaction pathway for the formation of $\mathrm{TiO}_{2}$ during the hydrothermal synthesis using different acid concentrations
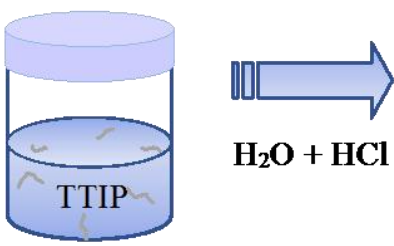

$\mathrm{H}_{2} \mathrm{O}+\mathrm{HCl}$
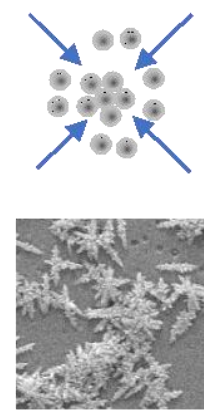

Nucleation
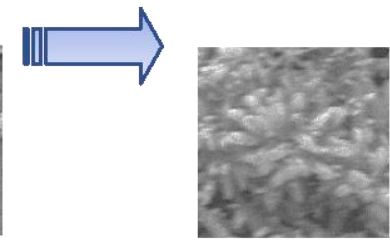

Oriented

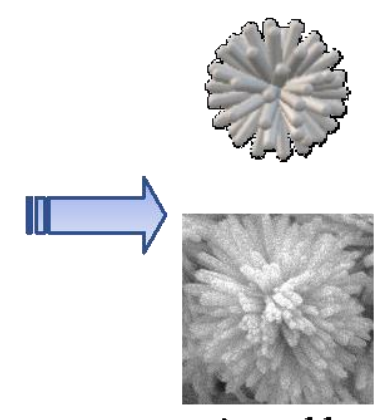

Assembly

Figure 5 Growth mechanism for the 3D architecture of the nano rosette rutile $\mathrm{TiO}_{2}$

At the initial stage, after a certain time spent in the hydrothermal reaction in an acid environment, nucleation takes place and the nuclei start to deposit on the substrate. As more time is spent in the hydrothermal reaction, the acid environment prevents the occurrence of agglomeration and favors the homogeneous nucleation of tiny single crystals derived from the nuclei. As the reaction continues, the crystals come together, forming the early stage of rosetteshaped formations through oriented attachments, while the acid concentration acts as a structure-directing agent. At the last stage of the hydrothermal reaction, the acid concentration helps to control the growth of the different crystals' orientation to minimize their surface area and decrease their energy. At the same time, the assembly occurs through the self-organization of the petal-shaped structures and the 3D hierarchical structures of the nano rosette rutile $\mathrm{TiO}_{2}$ is obtained. Finally, the calcination completes the crystallization while keeping the morphology. 


\section{CONCLUSION}

The characteristics of nano rosette $\mathrm{TiO}_{2}$ grown on a glass substrate via a hydrothermal reaction using different reaction times and acid concentrations have been examined. The morphological study from secondary electron images shows that after 3 hours of hydrothermal reaction time, the nucleation process has just taken place; the formation of the 3D hierarchical architecture of the nano rosettes is completed after 6 hours. The morphological and structural studies using different acid concentrations showed that the acid environment is a dominant factor in determining the 3D architecture of nano rosette $\mathrm{TiO}_{2}$. In pure water, there was no tendency to form 3D structures except for the anatase nanoparticle $\mathrm{TiO}_{2}$. In an acid environment, however, depending on the acid concentration, there is the driving force to form $3 \mathrm{D}$ structures. The formation of 3D architecture with Mimosa pudica petal-shaped rutile $\mathrm{TiO}_{2}$ occurred in a water and $\mathrm{HCl}$ ratio of $1: 1$, confirmed by the X-ray diffractograms indexed to rutile $\mathrm{P} 42 / \mathrm{mnm}$ with lattice parameters of $a=4.557(6) \AA$ and $c=2.940(5) \AA$. For the reaction pathway, the growth of $\mathrm{TiO}_{2}$ is determined by the reaction environment. In the absence of acid, there is more $\mathrm{OH}^{-}$ and the growth of $\mathrm{TiO}_{2}$ occurs via an edge-sharing mechanism to form anatase crystal structures. In the presence of an acid environment, however, there is less $\mathrm{OH}^{-}$and thus the growth occurs via a corner-sharing mechanism to form rutile crystal structure. This reaction pathway also determines the growth mechanism to form the 3D hierarchical nano rosette architecture.

\section{ACKNOWLEDGEMENT}

This work was funded by the Directorate of Research and Community Services (DRPM) Universitas Indonesia under the grant Hibah PITTA No. 2504/UN2.R3.1/HKP.05. 00/2018.

\section{REFERENCES}

Bai, J., Zhou, B., 2014. Titanium Dioxide Nanomaterials for Sensor Applications. Chemical Reviews, Volume 114(19), pp. 10131-10176

Banfield, J.F., Veblen, D.R., 1992. Conversion of Perovskite to Anatase and $\mathrm{TiO}_{2}$ (B): A TEM Study and the Use of Fundamental Building Blocks for Understanding Relationships among the $\mathrm{TiO}_{2}$ Minerals. American Mineralogist, Volume 77(5-6), pp. 545-557

Bu, J., Fang, J., Leow, W.R., Zheng, K., Chen, X., 2015. Single-crystalline Rutile $\mathrm{TiO}_{2} \mathrm{Nano}^{-}$ flower Hierarchical Structures for Enhanced Photocatalytic Selective Oxidation from Amine to Imine. RSC Advances, Volume 5, pp. 103895-103900

Cargnello, M., Gordon, T.R., Murray, C.B., 2014. Solution-phase Synthesis of Titanium Dioxide Nanoparticles and Nanocrystals. Chemical Reviews, Volume 114(19), pp. 93199345

Fisli, A., Ridwan, Krisnandi, Y.K., Gunlazuardi, J., 2017. Preparation and Characterization of $\mathrm{Fe}_{3} \mathrm{O}_{4} / \mathrm{SiO}_{2} / \mathrm{TiO}_{2}$ Composite for Methylene Blue Removal in Water. International Journal of Technology, Volume 8(1), pp. 76-84

Govindaraj, R., Santhosh, N., Pandian, M.S., Ramasamy, P., 2017. Synthesis of Nanocrystalline $\mathrm{TiO}_{2}$ Nanorods via Hydrothermal Method: An Efficient Photoanode Material for Dye Sensitized Solar Cells. Journal of Crystal Growth, Volume 468, pp. 125-128

Govindasamy, G., Murugasen, P., Sagadevan, S., 2016. Investigations on the Synthesis, Optical and Electrical Properties of $\mathrm{TiO}_{2}$ Thin Films by Chemical Bath Deposition (CBD) Method. Materials Research, Volume 19(2), pp. 413-419

Hagfeldt, A., Grätzel, M., 1995. Light Redox Reactions in Nanocrystalline Systems. Chemical Reviews, Volume 95(1), pp. 49-68

Hanaor, D.A.H., Sorrell, C.C., 2011. Review of the Anatase to Rutile Phase Transformation. Journal of Materials Science, Volume 46(4), pp. 855-874 
Jia, D., Qi, Z., Li, X., Li, L., Shao, L-H., Liu, H., 2017. 3D Hierarchical Macro/Mesoporous $\mathrm{TiO}_{2}$ with Nanoporous or Nanotubular Structures and Their Core/Shell Composites Achieved by Anodization. CrystEngComm, Volume 18, pp. 2509-2516

Longoni, G., Cabrera, R.L.P., Polizzi, S., D’Arienzo, M., Mari, C.M., Cui, Y., Ruffo, R., 2017. Shape-controlled $\mathrm{TiO}_{2}$ Nanocrystals for Na-ion Battery Electrodes: The Role of Different Exposed Crystal Facets on the Electrochemical Properties. Nano Letters, Volume 17(2), pp. 992-1000

Ma, J., Ren, W., Zhao, J., Yang, H., 2017. Growth of $\mathrm{TiO}_{2}$ Nanoflowers Photoanode for DyeSensitized Solar Cells. Journal of Alloys and Compounds, Volume 692, pp. 1004-1009

Nakata, K., Fujishima, A., 2012. $\mathrm{TiO}_{2}$ Photocatalysis: Design and Applications. Journal of Photochemistry and Photobiology C: Photochemistry Reviews, Volume 13(3), pp. 169-189

Ochiai, T., Fujishima, A., 2012. Photoelectrochemical Properties of $\mathrm{TiO}_{2}$ Photocatalyst and Its Applications for Environmental Purification. Journal of Photochemistry and Photobiology C: Photochemistry Reviews, Volume 13(4), pp. 247-262

Saif, M., Aboul-Fotouh, S.M.K., El-Molla, S.A., Ibrahim, M.M., Ismail, L.F.M., 2012. Improvement of the Structural, Morphology, and Optical Properties of $\mathrm{TiO}_{2}$ for Solar Treatment of Industrial Wastewater. Journal of Nanoparticle Research, Volume 14, pp. $101-111$

Sofyan, N., Ridhova, A., Yuwono, A.H., Udhiarto, A., 2017. Fabrication of Solar Cells with $\mathrm{TiO}_{2}$ Nanoparticles Sensitized using Natural Dye Extracted from Mangosteen Pericarps. International Journal of Technology, Volume 8(7), pp. 1229-1238

Wang, X., Hu, H., Yang, Z., Kong, Y., Fei, B., Xin, J.H., 2015. Visible Light-active Sub-5 nm Anatase $\mathrm{TiO}_{2}$ for Photocatalytic Organic Pollutant Degradation in Water and Air, and for Bacterial Disinfection. Catalysis Communications, Volume 72, pp. 81-85

Xiao, G., Shi, C., Li, L., Zhang, Z., Ma, C., Lv, K., 2017. 200-nm Length $\mathrm{TiO}_{2}$ Nanorod Array with a Diameter of $13 \mathrm{~nm}$ and Areal Density of $1100 \mu \mathrm{m}-2$ for Efficient Perovskite Solar Cells. Ceramics International, Volume 43(15), pp. 12534-12539

Xie, J., Lü, X., Liu, J., Shu, H., 2009. Brookite Titania Photocatalytic Nanomaterials: Synthesis, Properties, and Applications. Pure and Applied Chemistry, Volume 81(12), pp. 2407-2415

Yanqing, Z., Erwei, S., Zhizhan, C., Wenjuna, L., Xingfang, H., 2001. Influence of Solution Concentration on the Hydrothermal Preparation of Titania Crystallites. Journal of Materials Chemistry, Volume 11, pp. 1547-1551

Yasin, A., Guo, F., Demopoulos, G.P., 2016. Aqueous, Screen-printable Paste for Fabrication of Mesoporous Composite Anatase-rutile $\mathrm{TiO}_{2}$ Nanoparticle Thin Films for (Photo)electrochemical Devices. ACS Sustainable Chem. Eng., Volume 4(4), pp. $2173-$ 2181

Yin, S., Hasegawa, H., Maeda, D., Ishitsuka, M., Sato, T., 2004. Synthesis of Visible-lightactive Nanosize Rutile Titania Photocatalyst by Low Temperature Dissolutionreprecipitation Process. Journal of Photochemistry and Photobiology A: Chemistry, Volume 163(1-2), pp. 1-8

Zhong, D., Jiang, Q., Huang, B., Zhang, W-H., Li, C., 2015. Synthesis and Characterization of Anatase $\mathrm{TiO}_{2}$ Nanosheet Arrays on FTO Substrate. Journal of Energy Chemistry, Volume 24(5), pp. 626-631

Zhou, J., Tian, G., Chen, Y., Wang, J.-Q., Cao, X., Shi, Y., Pan, K., Fu, H., 2013. Synthesis of hierarchical $\mathrm{TiO} 2$ nanoflower with anatase-rutile heterojunction as Ag support for efficient visible-light photocatalytic activity. Dalton Transactions. Volume 42, pp. 11242-11251

Zhu, Z., Lin, S-J., Wu, C-H., Wu, R-J., 2018. Synthesis of $\mathrm{TiO}_{2}$ Nanowires for Rapid $\mathrm{NO}_{2}$ Detection. Sensors and Actuators A, Volume 272, pp. 288-294 